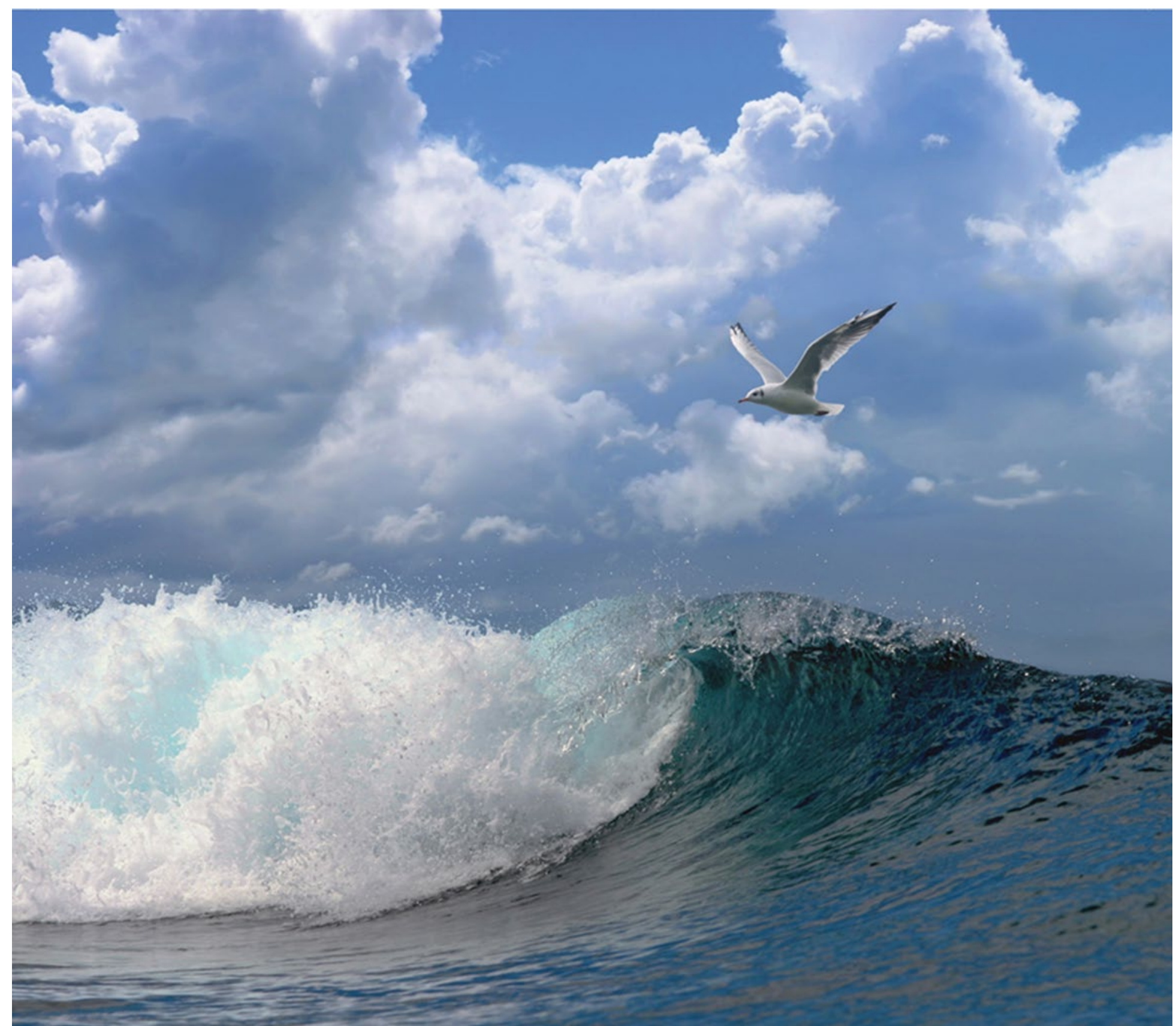

Plastic in Roodkeelduikers: een T-nul studie in het kader van de containerramp MSC Zoe 


\section{Plastic in Roodkeelduikers: een T-nul studie in het kader van de containerramp MSC Zoe}


Opdrachtgever: Rijkswaterstaat Noord-Nederland

Afdeling Netwerkontwikkeling en Visie

Attn.: Dhr. J. Doze

Postbus 2232

3500 GE Utrecht

BO-43-021.04-004

Dit rapport is gratis te downloaden van https://doi.org/10.18174/532730

Wageningen Marine Research verstrekt geen gedrukte exemplaren van rapporten.

Wageningen Marine Research is ISO 9001:2015 certified.

\section{(C) Wageningen Marine Research}

Wageningen Marine Research, instituut binnen de rechtspersoon Stichting Wageningen Research, hierbij vertegenwoordigd door Dr.ir. J.T. Dijkman, Managing director

KvK nr. 09098104, WMR BTW nr. NL 8113.83.696.B16. Code BIC/SWIFT address: RABONL2U IBAN code: NL 73 RABO 0373599285
Wageningen Marine Research aanvaardt geen aansprakelijkheid voor gevolgschade, noch voor schade welke voortvloeit uit toepassingen van de resultaten van werkzaamheden of andere gegevens verkregen van Wageningen Marine Research. Opdrachtgever vrijwaart Wageningen Marine Research van aanspraken van derden in verband met deze toepassing. Alle rechten voorbehouden. Niets uit deze uitgave mag weergegeven en/of gepubliceerd worden, gefotokopieerd of op enige andere manier gebruikt worden zonder schriftelijke toestemming van de uitgever of auteur. 


\section{Inhoud}

$\begin{array}{lr}\text { Samenvatting } & 4\end{array}$

$\begin{array}{llr}1 & \text { Inleiding } & 5\end{array}$

2 Onderzoeksvraag $\quad 6$

$3 \quad$ Materiaal en methode $\quad 7$

4 Resultaten $\quad 9$

$\begin{array}{llr}4.1 & \text { Maagsteentjes } & 9\end{array}$

$\begin{array}{lll}4.2 & \text { Non-food items } & 9\end{array}$

5 Discussie $r$

$6 \quad$ Kwaliteitsborging $\quad 12$

$\begin{array}{lr}\text { Referenties } & 13\end{array}$

$\begin{array}{lr}\text { Verantwoording } & 14\end{array}$ 


\section{Samenvatting}

In de eerste dagen van 2019 verloor het containerschip MSC Zoe in de Noordzeekustzone benoorden de Nederlandse en West-Duitse Waddeneilanden enkele honderden containers met inhoud. Een groot, maar onbekend deel van de verloren lading spoelde aan op de kusten van eilanden en het vasteland rond de Waddenzee; een onbekend deel bleef op zee. Veel items waren weliswaar "optisch vervuilend", maar vormden geen direct gevaar voor veel levensvormen in zee omdat ze bijvoorbeeld te groot waren om te kunnen worden gegeten. Echter, grote items kunnen op den duur verkruimelen tot kleinere stukjes (microplastics) die wel kunnen worden gegeten en bovendien verloor de MSC Zoe vele miljoenen plastic pellets van enkele $\mathrm{mm}$ doorsnede, die direct gegeten kunnen worden door bijvoorbeeld zeevogels.

Een van de kensoorten onder de zeevogels van de Noordzeekustzone is de Roodkeelduiker, Gavia stellata, die met duizenden exemplaren overwintert in juist deze zone en niet verder naar binnen (Waddenzee), dan wel naar buiten (op de open Noordzee). Roodkeelduikers hebben een breed dieet aan allerlei kleine vissen, uit alle waterlagen. Bovendien eten ze kleine steentjes, vermoedelijk om de vertering van de gegeten vissen te helpen bespoedigen. De combinatie van habitat, een breed dieet en het eten van steentjes, maakt dat deze beschermde vogelsoort kwetsbaar lijkt voor kleine plastic deeltjes in zee.

Wageningen Marine Research doet al vele jaren onderzoek naar het dieet van Roodkeelduikers in Nederland, door de maaginhoud van dood aangespoelde vogels te bestuderen. In de loop der jaren (1991-2020) konden zo de magen van 264 Roodkeelduikers worden bestudeerd. Hoewel het doel van deze studie dieetonderzoek was, zijn ook alle aangetroffen "plastics" en andere non-food items bewaard. Deze zijn, bij wijze van een nul-studie van de situatie voor het Zoe incident, aan een nader onderzoek onderworpen.

In de magen van 31 vogels (11.7\% van het totaal) werden in totaal 41 plastic-achtige voorwerpen aangetroffen, variërend van relatief zachte stukjes touw, vislijn, velletjes, tot harde scherven en andere objecten, inclusief vijf pellets. Op grond van deze resultaten concluderen we dat sommige materialen die door de MSC Zoe zijn verloren, met name de pellets, hun weg naar deze vogels zullen kunnen vinden. Aan de andere kant werden nooit dodelijke hoeveelheden, of zelfs maar (op het oog) gevaarlijke hoeveelheden plastics in de dood gevonden vogels aangetroffen, en waren er ook geen tekenen dat er na de ramp met de MSC Zoe opeens veel dode Roodkeelduikers op de Nederlandse stranden aanspoelden. 


\section{$1 \quad$ Inleiding}

In de eerste dagen van 2019 verloor het containerschip MSC Zoe in de Noordzeekustzone benoorden de Nederlandse en West-Duitse Waddeneilanden enkele honderden containers met inhoud. Een groot, maar onbekend deel van de verloren lading spoelde aan op de kusten van eilanden en het vasteland rond de Waddenzee; een onbekend deel bleef op zee. Meteen nadat de omvang van de vervuiling, veroorzaakt door het incident duidelijk was geworden, werden er vragen gesteld over de effecten van de vervuiling. Naast een overduidelijke "optische" vervuiling van stranden, kwelders, dijken, etc., was de vraag in hoeverre verloren materialen een impact zouden hebben op al dan niet beschermde diersoorten. Afgezien van het in zee spoelen van toxische stoffen, zouden ook inerte vaste materialen, zoals plastics, door dieren kunnen worden opgenomen. Mogelijke effecten zijn vervolgens:

verstrikking, verstikking, verlies van maagfunctie en voedselopname, alle met de dood als mogelijk ultiem gevolg. Er zijn legio voorbeelden van dieren die verstrikt raakten in plastics (en andere door mensen geproduceerde materialen) of die plastics aten en daar negatieve gevolgen van ondervonden (reviews in UNEP 2014; Kühn \& Van Franeker 2020).

De vervuiling door de MSC Zoe vond primair plaats in het Natura 2000-gebied Noordzeekustzone. Dit gebied is van groot belang als leefgebied voor een grote variatie aan diersoorten. Onder de zeevogels is een van de meest kenmerkende soorten van dit gebied de Roodkeelduiker, Gavia stellata. Deze soort broedt in noordelijk Europa en Amerika, en overwintert (in Europa) vrijwel exclusief in ondiepe kustwateren van Noord- en Oostzee (Voous 1960; Skov et al. 1995). De Nederlandse Noordzeekustzone neemt binnen dit overwinteringsgebied een belangrijke plaats in (Camphuysen \& Leopold 1994).

Roodkeelduikers hebben een breed dieet van kleine vissoorten (Leopold, in prep.). Het palet aan prooisoorten varieert van kleine stekelbaarzen en grondels, tot forse wijtingen en haringen, van pelagische vissoorten (vissen uit de waterkolom) tot demersale soorten (bodemvissen) en omvat zowel rondvissen als platvissen. Roodkeelduikers "bemonsteren", via hun dieet dus de hele waterkolom en een breed spectrum aan vissoorten, die zelf plastic zouden kunnen eten. Van "duikers" (meerdere soorten) is bovendien bekend dat ze steentjes van de bodem oppikken en die als "maagstenen" binnen houden, vermoedelijk om de gegeten vissen sneller te kunnen verteren. Deze gewoonte maakt het mogelijk dat zij ook andere materialen inslikken die op de zeebodem terecht komen en die de grootte hebben van de steentjes die ze gewoon zijn te "eten", zoals zinkende microplastics. Dergelijke artefacten zijn ook daadwerkelijk gevonden in Roodkeelduikers, met name in slachtoffers van een olie-incident bij Shetland (Weir et al. 1997; Kühn \& Van Franeker 2020). Van IJsduikers, Gavia immer, en Pacifische Duikers, Gavia pacifica, twee grotere, nauw verwante soorten, is in Noord-Amerika meermalen vastgesteld dat ze naast steentjes ook loodkorrels eten. Deze loodkorrels zijn afkomstig van de jacht op watervogels (loodhagel) of van de hengelsport (loodjes) en kunnen, eenmaal door de vogels ingeslikt, leiden tot loodvergiftiging (Locke et al. 1982; Pokras \& Chafel 1992; Wilson et al. 2004). Deze loodkorrels vallen binnen het groottespectrum van de opgenomen maagsteentjes (Franson et al. 2001), en zijn ook ongeveer even groot als bijvoorbeeld de plastic pellets die massaal in zee rondzwerven en waarvan er ook vele miljoenen door de MSC Zoe zijn verloren, in de Noordzeekustzone. 


\section{Onderzoeksvraag}

Van de ecologie van Roodkeelduikers in de Noordzeekustzone is weinig bekend. Om die reden doet Wageningen Marine Research onderzoek aan dood gevonden exemplaren. Biometrie, rui, conditie, doodsoorzaken en dieet worden onderzocht. Dit is een onderzoek met een lage intensiteit en een lange looptijd, omdat de mortaliteit onder deze lang levende zeevogels laag is, en er iedere winter maar weinig exemplaren worden gevonden en aangeboden voor onderzoek. Inmiddels zijn echter de magen van meer dan 200 Roodkeelduikers onderzocht en kan aan de hand van dit materiaal worden nagegaan of in deze soort, naast voedselresten en maagsteentjes, ook plastics etc. worden aangetroffen en of deze ken-soort voor de Noordzeekustzone dus gevoelig zou kunnen zijn voor (een deel van) de materialen die bij de MSC Zoe containerramp overboord geslagen zijn. Met name de verloren plastic pellets lijken hierbij kandidaten voor opname door Roodkeelduikers, gezien het aantal verloren items en hun grootte.

In het jaar van de ramp met de MSC Zoe werd slechts een enkele Roodkeelduiker aangeboden voor onderzoek. Er waren ook geen berichten van excessieve sterfte onder Roodkeelduikers. De huidige studie is daardoor alleen een T-nul studie. De onderzoeksvraag luidt: in welke mate worden artefacten gegeten door Roodkeelduikers, cq aangetroffen in de magen van in Nederland dood gevonden vogels, wat is de aard van deze artefacten en vallen de pellets, die in grote aantallen zijn verloren door de MSC Zoe binnen het spectrum van artefacten die in Roodkeelduikers (kunnen) worden aangetroffen? Het antwoord op deze vraag is belangrijk voor het bepalen of de Roodkeelduiker, een van de kensoorten onder de zeevogels van de Noordzeekustzone, een geschikte soort is voor monitoring van de ecologische effecten van het Zoe incident op de langere termijn. 


\section{Materiaal en methode}

Dode Roodkeelduikers werden vooral verzameld door tellers van de Nederlandse Zeevogelgroep, die systematisch de kustlijn afzoeken op dode vogels in het kader van onderzoek naar olieslachtoffers (Camphuysen 1995; 2019; Camphuysen \& Heubeck 2003). Middels een aantal gerichte oproepen werden tellers verzocht om alle gevonden duikers mee te nemen voor onderzoek. Anderen die van deze oproepen hoorden hebben ook enkele vogels aangeleverd. Roodkeelduikers zijn zelden talrijk dood op de kust te vinden: gemiddeld werden $9 \pm 11$ vogels per jaar aangeleverd. De relatief hoge standaarddeviatie wordt veroorzaakt door enkele incidenten, zoals olierampen, lozingen van andere kleverige vloeistoffen, en lokale massa-verdrinkingen in staand want. De aantallen aangeboden vogels liepen uiteen van 0-41 per jaar (Tabel 1).

Tabel 1. De aantallen onderzochte Roodkeelduikers per jaar (1991-2020; $n=264)$. Aantallen die op de Noordzeekusten van de Waddeneilanden, respectievelijk in de Waddenzee werden gevonden, staan apart vermeld, als onderdeel van de totale aantallen.

\begin{tabular}{|c|c|c|c|}
\hline Jaar & Totaal & Waddenkust & Waddenzee \\
\hline 1991 & 1 & 1 & 0 \\
\hline 1993 & 1 & 0 & 1 \\
\hline 1994 & 1 & 1 & 0 \\
\hline 1995 & 2 & 2 & 0 \\
\hline 1996 & 21 & 4 & 3 \\
\hline 1997 & 12 & 0 & 2 \\
\hline 1998 & 16 & 3 & 5 \\
\hline 1999 & 8 & 3 & 4 \\
\hline 2000 & 6 & 2 & 2 \\
\hline 2001 & 4 & 0 & 2 \\
\hline 2002 & 40 & 12 & 17 \\
\hline 2003 & 41 & 5 & 13 \\
\hline 2004 & 10 & 3 & 3 \\
\hline 2005 & 9 & 0 & 5 \\
\hline 2006 & 14 & 6 & 6 \\
\hline 2007 & 5 & 1 & 3 \\
\hline 2008 & 4 & 1 & 2 \\
\hline 2009 & 6 & 2 & 1 \\
\hline 2010 & 7 & 3 & 3 \\
\hline 2011 & 2 & 1 & 0 \\
\hline 2012 & 18 & 2 & 0 \\
\hline 2013 & 0 & 0 & 0 \\
\hline 2014 & 30 & 1 & 0 \\
\hline 2015 & 2 & 2 & 0 \\
\hline 2016 & 0 & 0 & 0 \\
\hline 2017 & 1 & 0 & 0 \\
\hline 2018 & 1 & 1 & 0 \\
\hline 2019 & 1 & 0 & 0 \\
\hline 2020 & 1 & 1 & 0 \\
\hline
\end{tabular}


Roodkeelduikers zijn in Nederland wintergasten (Camphuysen \& Leopold 1994). Dit wordt gereflecteerd in de verdeling van de aangeleverde vogels over de maanden van het jaar (Figuur 1): de aantallen zijn het hoogst tussen november en maart. De ramp met de MSC Zoe in januari 2019 viel dus in de piek van het voorkomen van Roodkeelduikers voor de Nederlandse kust.

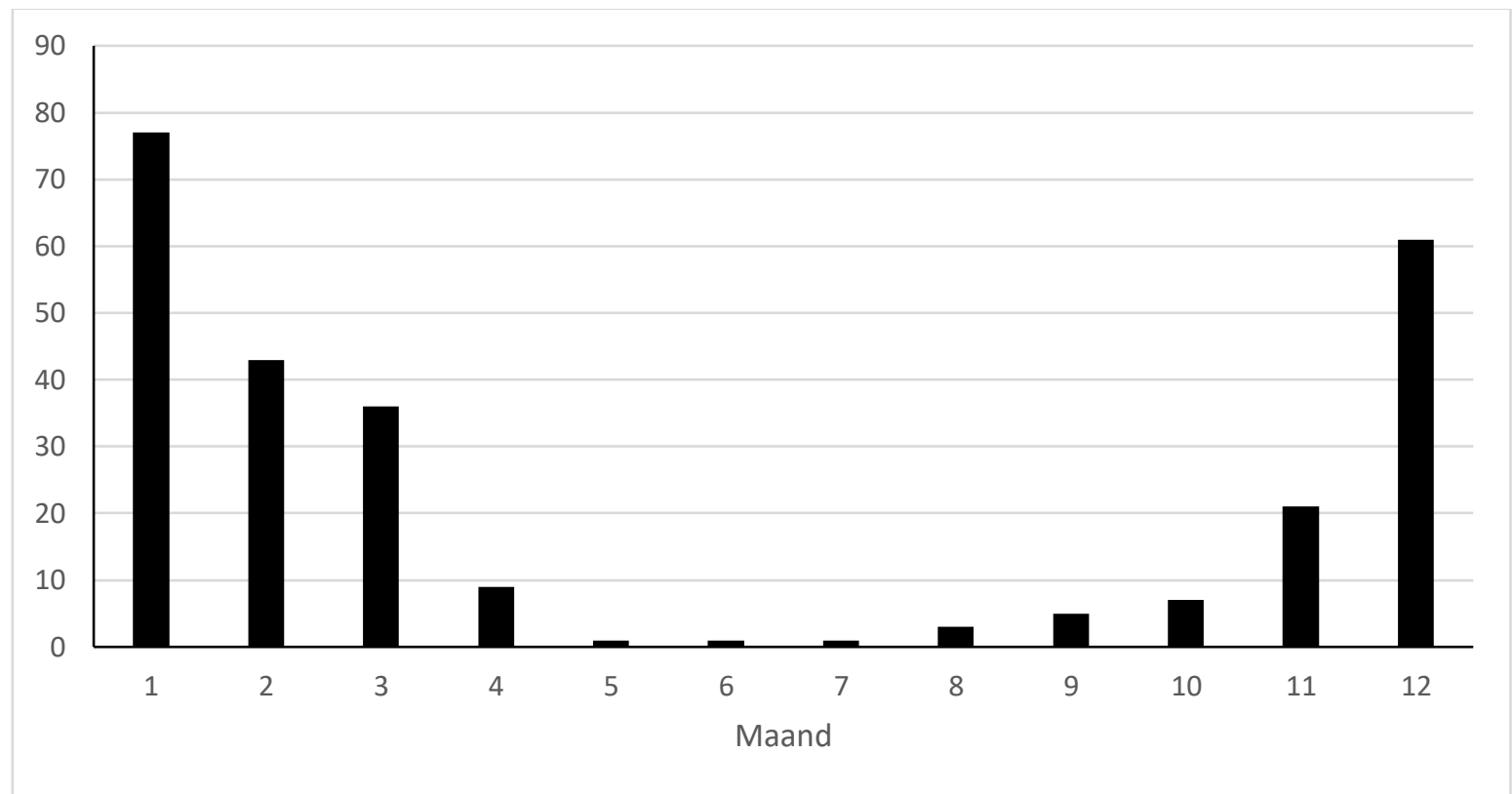

Figuur 1. De aantallen onderzochte Roodkeelduikers per maand (1991-2020; $n=264$ ) langs de Nederlandse kust.

Het onderzoek aan de dood gevonden Roodkeelduikers was primair gericht op het dieet van deze vogels. Daartoe werden maag en darm uit de vogel genomen, in de lengte open geknipt en met water uitgespoeld in een groot bekerglas. Vervolgens werd dit bekerglas onder een langzaam stromende waterkraan gezet. Het water deed het bekerglas overstromen en lichte delen (restjes visvlees, slijm, bloed, etc) werden zo afgevoerd. Na circa 10 minuten bleef helder water over en op de bodem van het bekerglas lagen alle relatief zware prooiresten, steentjes en andere artefacten. Van meet af aan is ook gekeken naar plastics in de maag en dan vooral naar het voorkomen van plastic pellets, omdat het uit werk aan Noordse Stormvogels (Fulmarus glacialis) al duidelijk was geworden dat deze in magen van zeevogels kunnen voorkomen (van Franeker 1985). Omdat pellets, en andere vormen van plastic echter relatief licht zijn, valt niet uit te sluiten dat incidenteel plastics uit de monsters zijn weggespoeld, ook al werd hierop bij het spoelen wel steeds het oog op gehouden.

Alle harde prooiresten en artefacten zijn gedroogd, gedetermineerd, gewogen en gemeten, in een database gezet en vervolgens bewaard. Voor dit rapport zijn de bewaarde monsters opnieuw bekeken en zijn items die plastic zouden kunnen zijn bestudeerd onder een Fourier Transform Infrarood spectroscoop (FTIR; IRSpirit Shimadzu, golflengte 400-4000nm; zie Kühn et al. 2020) om het type "plastic" te kunnen vaststellen.

De onderzochte vogels zijn niet speciaal voor dit onderzoek verzameld. Op onderzoek aan dood gevonden dieren is kritiek mogelijk in die zin dat dode vogels niet per se een goede weergave zijn van de populatie levende dieren. Slechts een kleine minderheid van de vogels is door een veterinaire patholoog onderzocht, maar voor de meest individuen kon wel een vermoedelijke doodsoorzaak worden vastgesteld op grond van uiterlijke afwijkingen of duidelijke pathologie van de organen. Sommige vogels waren duidelijk een acute dood gestorven ("uit het leven weggerukt"), zoals vogels die dik onder de olie of andere kleverige substanties zaten of die waren verdronken in staand want. Dergelijke vogels hadden vaak een goede lichaamsconditie, en waren onder meer herkenbaar aan een laag onderhuids vet, vetlichamen op en tussen de inwendige organen en een goede bespiering. Andere vogels waren een langzame dood gestorven, en misten (vrijwel) alle vet en hadden ingevallen spieren. Typische voorbeelden van deze laatste groep waren vogels met kleine hoeveelheden olie op het verenkleed en vogels met allerlei inwendige ziektebeelden: gezwellen, schimmelinfecties, darmverstoppingen. 


\section{Resultaten}

\subsection{Maagsteentjes}

De magen van in totaal 264 Roodkeelduikers zijn onderzocht. De meerderheid van de onderzochte vogels zijn gevonden, en vermoedelijk gestorven in de winter: 68,5\% kwam uit de maanden december-februari (Figuur 1).

Acht vogels bleken, na opening van het karkas, geen maag meer te hebben (uitgepikt door aaseters): deze zijn niet meegerekend bij het totaal van 264 onderzochte vogels (magen). 20 magen bevatten geen enkel maagsteentje of artefact. In alle overige 244 magen ( $92 \%$ van de onderzochte magen) werden steentjes in de magen aangetroffen. Vanwege de grillige vormen zijn deze niet opgemeten maar individueel gewogen, waarbij er steeds een onderscheid gemaakt moest worden tussen zandkorrels en steentjes. De kleinste steentjes waren ongeveer $2 \mathrm{~mm}$ in doorsnede, de grootste ruim $1 \mathrm{~cm}$. Kleinere "steentjes" dan circa $2 \mathrm{~mm}$ zijn beschouwd als zandkorrel, en niet meegenomen.

Het aantal steentjes per maag varieerde van 0 tot 40. In totaal werden in de onderzochte vogels 2162 steentjes aangetroffen, gemiddeld waren er $8,2 \pm 7,4$ steentjes per maag. Gemiddeld wogen de

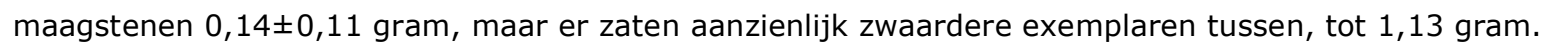
De maag met de meeste steentjes (40) had ook het hoogste totaal gewicht aan steentjes: 5,85 gram, maar gemiddeld bevatte een maag $1,21 \pm 1,18$ gram aan steentjes.

\subsection{Non-food items}

In totaal werden in de magen van 34 vogels non-food items gevonden, waarvan het merendeel "plastic-verdacht" was. Uitzonderingen waren een stalen vismerk (dat kon worden herleid naar een "Sloeharing": een groot haring-ras dat leeft voor de kust van Noorwegen (Leopold 1997)); een stukje materiaal dat werd aangezien voor 'silicone' maar dat nadat het was getest organisch bleek te zijn (vermoedelijk een stukje menselijke nagel); de schacht van een langwerpige vishaak (palinghaak); en een stukje hout. Een aangetroffen klodder "vet" behoort ook niet tot de "plastics", maar leek wel door mensen gemaakt.

Naast bovengenoemde non-food items werden 41 plastic-achtige voorwerpen in de magen van 31 verschillende vogels aangetroffen, variërend van relatief zachte stukjes touw, vislijn, velletjes, tot harde scherven en andere objecten, inclusief vijf pellets en een plastic "kogeltje". Dit betekent dat in $11,7 \%$ (31 van de 264) van de onderzochte vogels plastic-achtige artefacten werden aangetroffen (Tabel 2). Mogelijk is een deel van de items per abuis aangezien als voedsel (sommige draadjes hadden ongeveer de vorm en omvang van bijvoorbeeld een kleine zandspiering) terwijl andere items wellicht als surrogaat-maagsteentjes zijn opgepikt. Een andere optie is dat items met prooivissen mee naar binnen zijn gekomen. Van geen enkel item bestond tijdens de sectie het vermoeden dat het de dood van de vogel had veroorzaakt: daarvoor waren de items te klein, hadden geen verstopping veroorzaakt of de maagwond doorboord (zelfs de stalen vishaak-schacht niet).

De FTIR bracht een verscheidenheid aan plastic typen aan het licht (Tabel 2), wat representatief lijkt voor wat er in zee rond drijft (Kühn et al. 2020a,b). Van enkele stukjes "plastic" konden niet met zekerheid worden bepaald om welk type materiaal het ging (Score <800, zie Tabel 2), bijvoorbeeld doordat het materiaal sterk verweerd was. Deze "Score" geeft de mate van overlap aan tussen het gemeten materiaal spectrum en het best bijpassende spectrum onder de beschikbare materiaalspectra (FTIR; IRSpirit Shimadzu). 
Tabel 2. De non-food items aangetroffen in de magen van 264 onderzochte Roodkeelduikers. De "Score" geeft een betrouwbaarheidswaarde aan (0-1000). Alleen waardes boven de 800 worden als betrouwbaar beschouwd voor plastic identificatie.

\begin{tabular}{|c|c|c|c|c|c|c|c|}
\hline Vogel-ID & Materiaal & Score & Type & Item & $\begin{array}{l}\text { Lengte } \\
(\mathrm{mm})\end{array}$ & $\begin{array}{l}\begin{array}{l}\text { Breedte } \\
(\mathrm{mm})\end{array} \\
\end{array}$ & $\begin{array}{l}\text { Massa } \\
\text { (g) }\end{array}$ \\
\hline RKD-07/01/97 Den Helder & Ionomeer & 859 & stukje touw & draad & 83,6 & 0,37 & 0,01 \\
\hline RKD-21/01/97 Westkapelle & Polymethylmethacrylaat & 961 & plastic kogeltje & bol & 2,32 & 2,3 & 0,0058 \\
\hline RKD-19/02/97 Den Helder & staal & & vismerk & $\operatorname{tag}$ & 20 & 3,97 & 0,38 \\
\hline RKD-10/01/99 TX-paal 27 & Polystyreen & 937 & plastic & staaf & 18,89 & 5,44 & 0,24 \\
\hline RKD-20/01/99 TX-Redoute & HDPE & 912 & plastic & pellet & 4,13 & 3,77 & 0,02 \\
\hline RKD-10/01/99 Harlingen & Polyethylene & 853 & nylon & draad & 19 & 0,46 & 0,0029 \\
\hline RKD-jan-/2002 Harlingen & lonomeer & 876 & touw & touw & 25 & 0,5 & 0,0042 \\
\hline RKD-30/11/2002 TX-paal 12 & Polyethyleen & 877 & bol & pellet & 5,92 & 5,45 & 0,0188 \\
\hline RKD-11/12/2002 TX-Mok & Polyethyleen & 879 & nylon & maas van net & 16,5 & 0,28 & 0,05 \\
\hline RKD-11/12/2002 TX-Mok & Polyethyleen & 879 & nylon & maas van net & 13 & 0,45 & \\
\hline RKD-5/12/2002 Vlieland-één & Polyethyleen & 847 & bol & pellet & 3,14 & 2,34 & 0,01 \\
\hline RKD-10/12/2002 Vlieland-drie & nd & & bol ("pellet) & zoek??? & & & \\
\hline RKD-13/01/2003 TX-één & Organisch & 882 & nagel? & scherf & 6,58 & 1,63 & 0,0033 \\
\hline RKD-30/01/2003 Tricolor \# 358 & staal & & palinghaak & staal & 32,4 & 0,89 & 0,15 \\
\hline RKD-30/01/2003 Tricolor \# 358 & Ionomeer & 853 & draad & draad & 95 & 0,25 & 0,01 \\
\hline RKD-05/12/2002 West Kapelle & Ionomeer & 854 & draad & draad & 19 & 0,45 & 0,00 \\
\hline RKD-01/02/2003 Walcheren-2 & nd & & vet (niet bewaard) & klodder & & & 0,01 \\
\hline RKD-17/11/2003 TX-wadkant & Polypropyleen & 826 & touw (vergaan) & kluwen & 15 & 5 & 0,03 \\
\hline RKD-17/11/2003 TX-wadkant & Polyamide (Nylon) & 912 & bol & pellet & 3,91 & 3,18 & 0,02 \\
\hline RKD-29/12/2002 TX-Hors-3 & Ionomeer & 872 & touw & kluwen & & & 0,0380 \\
\hline RKD-29/12/2002 TX-Hors-4 & nd & & touw & zoek??? & 21,15 & & 0,00 \\
\hline RKD-07/10/2003 Lauwersoog & Polypropyleen & 863 & plastic & vel wit & 14 & 12 & 0,01 \\
\hline RKD-07/10/2003 Lauwersoog & onbekend & 792 & plastic & vel zwart & 16 & 10 & 0,02 \\
\hline RKD-07/10/2003 Lauwersoog & onbekend & 792 & plastic & vel zwart & 14 & 10 & 0,02 \\
\hline RKD-eind dec 2005 Fugelpits- 1 & Polypropyleen & 899 & plastic & fragment & 5,75 & 4,32 & 0,01 \\
\hline RKD-24/12/2005 Afsluitdijk & Ionomeer & 823 & plastic & draad & 15,8 & 0,3 & 0,0001 \\
\hline RKD-23/09/2006 Vlieland & nd & & plastic & zoek??? & & & \\
\hline RKD-29/10/2006 Texel strand & HDPE & 876 & plastic & fragment & 6,04 & 4,01 & 0,0059 \\
\hline RKD-29/10/2006 Texel strand & Polypropyleen & 801 & plastic & draad & 16,8 & 0,3 & 0,0163 \\
\hline Texel 31-10-2006 & Polypropyleen & 867 & touw & $\begin{array}{l}\text { kluwen } \\
\text { (matrix) }\end{array}$ & 30 & 10 & 0,21 \\
\hline Texel 31-10-2006 & Polyethylene & 924 & touw wit & in de kluwen & & & \\
\hline Texel 31-10-2006 & Polyethylene & 895 & touw groen & in de kluwen & & & \\
\hline RKD-24/12/2007 Oudeschild & lonomeer & 805 & nylon & touw & 18,1 & 0,3 & 0,0001 \\
\hline RKD-24/12/2007 Oudeschild & lonomeer & 777 & nylon & touw & 10 & 0,3 & 0,0001 \\
\hline RKD-2/1/2009 TX TESO haven & Polypropyleen & 819 & touw (vergaan) & kluwen & 10 & 2,75 & 0,0082 \\
\hline RKD-23/01/2009 Texel Hors & Polypropyleen & 825 & touw (vergaan) & kluwen & 6 & 5 & 0,0196 \\
\hline RKD 09-01-2009 Den Helder & Polypropyleen & 775 & touw (vergaan) & kluwen & 7 & 2 & 0,0059 \\
\hline RKD NZEE-Noordwijk 222 & Polyamide (Nylon) & 829 & plastic & borstel & 4,09 & 0,7 & 0,0001 \\
\hline RKD TX 13-2-2012 TX waddijk & Polypropyleen & 866 & plastic & vel & 21,5 & 9 & 0,01 \\
\hline RKD-12-01-2014 Egmond-254 & Polyethyleen & 920 & touw & kluwen & & 0,4 & 0,03 \\
\hline RKD-12-01-2014 Egmond-258 & hout & & hout & & 1,45 & 1,12 & 0,0001 \\
\hline RKD-7-11-2015 TX-Westerslag & Polypropyleen & 918 & stukje touw & draad & 21 & 0,15 & 0,0014 \\
\hline RKD-7-11-2015 TX-Westerslag & lonomeer & 825 & plastic & vel & 20 & 3,3 & 0,0047 \\
\hline RKD-7-11-2015 TX-Westerslag & Ionomeer & 836 & plastic & vel & 26 & 3,3 & 0,0071 \\
\hline RKD TX-Ecomare 18-3-2020 & Polypropyleen & 857 & touw & kluwen & & & \\
\hline
\end{tabular}

*: Ionomeer: een plastic type dat antistatisch is. Wordt als isolatie van elektrische kabels etc. gebruik

Polymethylmethacrylaat: hiervan worden onder meer plexiglas gemaakt Polystyreen: piepschuim
Polyethyleen: de meest gebruikte kunststof (plastic) HDPE: high density polyethyleen

Polyamide: nylon

Polypropyleen: samen met polyethyleen de meest gebruikelijke plastics 


\section{$5 \quad$ Discussie}

Uit een periode van meerdere decennia voorafgaand aan de ramp met de MSC Zoe konden -voor ander onderzoek- voldoende Roodkeelduikers worden verzameld om een beeld te schetsen van de mogelijkheid dat deze kensoort van de Noordzeekustzone plastic zou kunnen inslikken. Het brede dieet van deze vogels, en het feit dat ze gewoonlijk steentjes eten, vermoedelijk om de vertering te bespoedigen, deed vermoeden dat de Roodkeelduiker een soort zou zijn waarin met enige regelmaat plastics gevonden zou kunnen worden. Weliswaar lag het voor de hand dat de frequentie van voorkomen van plastics in de magen van Roodkeelduikers lager zou zijn dan bij de standaard soort voor monitoring, de Noordse Stormvogel, omdat deze laatste soort veel items van het wateroppervlak eet en daarbij niet erg kieskeurig lijkt te zijn (Van Franeker \& Kühn 2019), terwijl Roodkeelduikers duikend, levende vissen eten. Aan de andere kant zijn de pellets, die bij miljoenen verloren zijn door de MSC Zoe van vergelijkbare grootte als de maagsteentjes die vrijwel alle Roodkeelduikers opnemen. Ook is van belang, dat de Noordse Stormvogel veel meer een pelagische (offshore) zeevogel is, die minder geschikt lijkt om de effecten van een plastic spill in de kustwateren te monitoren, terwijl de Noordzeekuszone, waarin zich de ramp met de MSC Zoe afspeelde, bij uitstek het leefgebied is van de Roodkeelduiker. Het moment van de ramp, midden in de winter, viel ook in de piek van voorkomen van deze vogels in onze kustwateren.

De frequentie van voorkomen van plastic-achtige materialen werd bepaald op $11,7 \%$. Dit is een veel lager getal dan bij de Noordse Stormvogel (>90\%; Van Franeker \& Kühn 2019), maar nog altijd aanzienlijk. Van belang hierbij is ook dat een grote verscheidenheid aan vormen en materialen werd aangetroffen, waaronder pellets. De spectroscoop metingen aan de gevonden materialen tonen aan dat deze ook daadwerkelijk "plastics" waren en niet bijvoorbeeld stukjes wier of ander natuurlijk materiaal.

De conclusie van deze nul-studie moet zijn dat in Roodkeelduikers regelmatig plastic wordt aangetroffen en dat sommige materialen die door de MSC Zoe zijn verloren, met name de pellets, hun weg naar deze vogels zullen kunnen vinden. Aan de andere kant werden nooit dodelijke hoeveelheden, of zelfs maar (op het oog) gevaarlijke hoeveelheden plastics in de dood gevonden vogels aangetroffen, en waren er ook geen tekenen dat er na de ramp met de MSC Zoe opeens veel dode Roodkeelduikers op de Nederlandse stranden aanspoelden.

Uit modelsimulaties is naar voren gekomen dat de overgrote meerderheid van de verloren pellets inmiddels ergens op de kust moet liggen (Johan van der Molen, NIOZ, pers. comm.). Dit maakt, dat deze pellets dus niet meer relevant zijn voor zeevogels op zee. Gezonde Roodkeelduikers komen in Nederland niet aan land en zullen dus ook niet meer in aanraking kunnen komen met de pellets, tenzij, bijvoorbeeld als gevolg van storm en zeer hoog water, een deel van de pellets weer terugstroomt naar zee. Het ligt niet voor de hand om de Roodkeelduiker aan te bevelen voor verdere monitoring van gevolgen van het Zoe incident, omdat het deel van de verloren lading dat het meest in aanmerking komt om door deze vogels te worden ingeslikt, de pellets, niet meer beschikbaar zijn. Bovendien worden er jaarlijks geen grote aantallen dode Roodkeelduikers gevonden. Alleen in het uitzonderlijke geval, dat er als gevolg van een incident opeens veel (tientallen of meer) dode Roodkeelduikers beschikbaar komen (zoals bij een olie incident of bij een massale verdrinking in vistuig), verdient het aanbeveling om een dergelijke mogelijkheid voor onderzoek niet te laten lopen. 


\section{$6 \quad$ Kwaliteitsborging}

Wageningen Marine Research beschikt over een ISO 9001:2015 gecertificeerd kwaliteitsmanagementsysteem. Dit certificaat is geldig tot 15 december 2021. De organisatie is gecertificeerd sinds 27 februari 2001. De certificering is uitgevoerd door DNV GL. 


\section{Referenties}

Camphuysen C.J. 1995. Olieslachtoffers langs de Nederlandse kust als indicatoren van de vervuiling van de zee met olie. Sula 9(special issue): 1-90, I-XX.

Camphuysen C.J. 2019. A decline in oil rates consolidated: Monitoring and assessment of the proportion of oiled Common Guillemots in The Netherlands: winter 2018/19. NIOZ Report, RWS Centrale Informatievoorziening BM 19.29, Dec 2019. Royal Netherlands Institute for Sea Research, Texel. doi:10.13140/RG.2.2.18445.49128

Camphuysen C.J. \& Heubeck M. 2003. Marine oil pollution and beached seabirds: the development of a sensitive monitoring instrument. Envir. Poll. 112: 443-461.

Camphuysen C.J. \& Leopold M.F. 1994. Atlas of seabirds in the southern North Sea. IBN Research report 94/6, NIOZ Report 1994-8, Institute for Forestry and Nature Research, Netherlands Institute for Sea Research and Dutch Seabird Group, Texel, 126p.

http://publicaties.minienm.nl/documenten/atlas-of-seabirds-in-the-southern-north-sea

Van Franeker J.A. 1985. Plastic ingestion in the North Atlantic fulmar. Mar. Poll. Bull. 16:367-369.

Van Franeker J.A. \& Kühn S. 2019. Fulmar Litter EcoQO monitoring in the Netherlands - Update 2018. Wageningen Marine Research Report C077/19 \& RWS Centrale Informatievoorziening BM 19.16. doi:10.18174/486799

Franson J.C., Hansen S.P., Pokras M.A. \& Miconi R. 2001. Size characteristics of stones ingested by Common Loons. Condor 103: 189-191.

Kühn S. \& van Franeker J.A. 2020. Quantitative overview of marine debris ingested by marine megafauna. Mar. Poll. Bull. 151 (2020) 110858. doi:10.1016/j.marpolbul.2019.110858

Kühn S., van Franeker J.A., O’Donoghue A.M., Swiers A., Starkenburg M., van Werven B., Foekema E., Hermsen E., Egelkraut-Holtus M. \& Lindeboom H. 2020. Details of plastic ingestion and fibre contamination in North Sea fishes. Envir. Poll. 257: 113569. doi:10.1016/j.envpol.2019.113569

Leopold M. 1997. Onderzoek aan Roodkeelduikers in het Windbrekergebied. De Windbreker 99: 2-4.

Locke L.N., Kerr S.M. \& Zoromski D. 1982. Lead poisoning in Common Loons (Gavia immer). Avian Dis. 26: 392-396.

Pokras M.A. \& Chafel R. 1992. Lead toxicosis from ingested fishing sinkers in adult common loons (Gavia immer) in New-England. Journal of Zoo and Wildlife Medicine 23: 92-97.

Skov H., Durinck J., Leopold M.F. \& Tasker M.L. 1995. Important bird areas in the North Sea, including the Channel and the Kattegat. BirdLife International, Cambridge, 156p.

UNEP 2014. UNEP Year Book 2014 emerging issues update: Plastic Debris in the Ocean. United Nations Environment Programme, Nairobi. http://www.unep.org/yearbook/2014/PDF/chapt8.pdf.

Voous K.H. 1960. Atlas of European Birds. Nelson and sons Ltd, London 284p.

Weir D.N., Kitchener A.C., McGowan R.Y., Kinder A. \& Zonfrillo B. 1997. Origins, population structure, pathology and diet samples of diver and auk casualties of the Sea Empress oil spill. Final report by the National Museums of Scotland and University of Edinburgh to the Sea Empress Environmental Evaluation Committee, CCW Contract No. FC 73-02-69.

Wilson H.M., Oyen J.L. \& Sileo L. 2004. Lead shot poisoning of a Pacific Loon in Alaska. Journal of Wildlife Diseases 40: 600-602. 


\section{Verantwoording}

Rapport C088/20

Projectnummer: 4315100134

Dit rapport is met grote zorgvuldigheid tot stand gekomen. De wetenschappelijke kwaliteit is intern getoetst door een collega-onderzoeker en het verantwoordelijk lid van het managementteam van Wageningen Marine Research
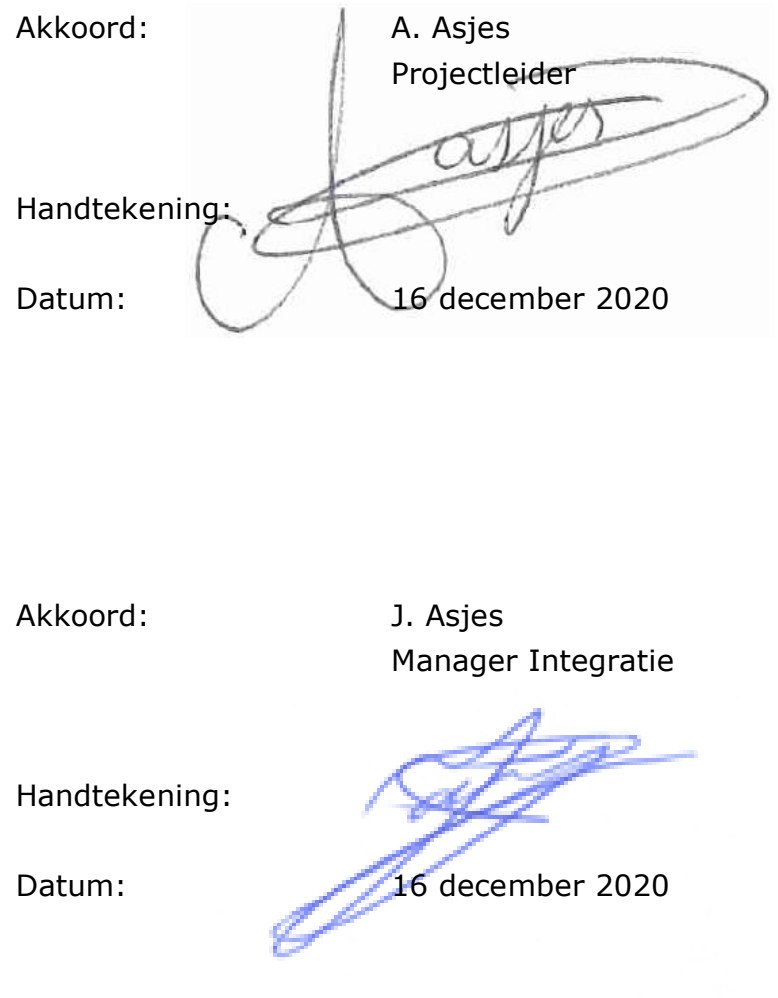
Wageningen Marine Research

$\mathrm{T}+31$ (0)317480900

E: marine-research@wur.nl

www.wur.eu/marine-research

Visitors' address

- Ankerpark 27, 1781 AG Den Helder

- Korringaweg 7, 4401 NT Yerseke

- Haringkade 1, 1976 CP IJmuiden
With knowledge, independent scientific research and advice, Wageningen Marine Research substantially contributes to more sustainable and more careful management, use and protection of natural riches in marine, coastal and freshwater areas.

Wageningen Marine Research is part of Wageningen University \& Research. Wageningen University \& Research is the collaboration between Wageningen University and the Wageningen Research Foundation and its mission is: 'To explore the potential for improving the quality of life' 